\title{
Editorial: Democratizing Knowledge on Ending Homelessness
}

International Journal on Homelessness, 2021, 1(1): page 1-2.

A young man sleeps on the streets of Accra, Ghana, having left his rural community to find work. A mom takes her two kids to a women's shelter in Sydney, Australia, escaping an abusive partner. Five Syrian families share a single room apartment in Turkey having fled war and seeking resettlement as refugees. A woman in Sao Paulo, Brazil is evicted from her apartment after the rent is increased beyond her means to pay. A gay youth in Belfast, Northern Ireland leaves the abuse of his family and finds himself in an emergency shelter. Five women share a tent in a park in Victoria, Canada where they are able to use substances in relative peace until by-law officers order them to move along.

Homelessness is a global phenomenon. In spite of global increases in gross domestic product (GDP) and global decreases in deaths due to armed conflict, representing a degree of increased social stability and wealth, homelessness persists or continues to grow. While every human being shares a need for suitable, adequate, and affordable housing, high housing costs and the presence of poverty mean that this need is not being met for many. While the cultural and policy contexts may vary significantly, the human desire and need to find home is ubiquitous. The Covid-19 pandemic has shed particular light on the deadly risk of being unhoused or inadequately housed. At the same time, many jurisdictions are demonstrating that dedicated focus on housing solutions driven by this crisis can lead to tangible results. This momentum needs to be sustained and adopted worldwide. Around the world we find ourselves with much work to do in order to prevent and end homelessness.

Thankfully, in understanding how to prevent and end homelessness, we have decades of wisdom upon which to build. Academics, service providers, people with lived experiences of homelessness, and policy makers have been sharing their knowledge and experiences both in public reports and scholarly literature. This has helped in evolving models for prevention, defining best practices in supporting journeys out of homelessness, shedding light on the distinct experiences of particular populations, and linking homelessness to broader systems such as housing, criminal justice, healthcare, and education. Many housing and homelessness journals have paved the way in making this knowledge accessible to the academic community - with some even being openly accessible to all.

And yet, in spite of all the good work that has gone before, a group of us has been left with the deep sense that we aren't telling the whole story, especially when the stories we are telling are not fully accessible to all. It's an uncomfortable reality for those in academia that no matter how you look at it, the vast majority of published scholarship on preventing and ending homelessness is western, or from the Global North, and written in English. The reality is that the vast wisdom of the most populated parts of our planet is primarily undocumented in research scholarship and program evaluations. This is not due to any unwillingness on the part of current venues for knowledge translation, but rather illustrates the fact that equity requires intentionality. To achieve truly global scholarship, we need to create intentional platforms for knowledge exchange that break down international barriers. We also need to support under-represented regions in having opportunities to create exceptional scholarship. This vision underpins the development of the International Journal on Homelessness.

To democratize knowledge on a global scale, to make it accessible and widely available, our Editorial Board has designed our processes with intentionality. This means:

- advertising our calls for papers in as many languages as possible;

- accepting and reviewing articles in as many languages as possible;

- having an authentically international Editorial Board;

- providing free open access; and 
- reaching out intentionally to regions that are under-represented in the literature to date.

While we acknowledge that we will learn as the journal evolves, our commitment to the democratization of knowledge is written into our by-laws - indeed, authentic internationalization is a requirement of our ongoing existence. This includes both the Global North and the Global South. We are thankful to Western University and the Institute of Global Homelessness for providing the practical and financial resources to help make this happen.

In this first editorial of the first journal edition, we invite you as people with lived or living experiences of homelessness, scholars, service providers, policy makers or others to join us in our mission of sharing knowledge to prevent and end homelessness. We need your submissions, your collective wisdom, to help create the change that we all believe in. Whether it's a discussion piece exploring experiences, opportunities, or ideas, or a traditional research article, we need your contributions to achieve our goals. Please join in this collective, international effort and together we absolutely can prevent and end homelessness worldwide.

Abe Oudshoorn, RN PhD, Managing Editor 